\title{
Biventricular repair versus Fontan completion for patients with d- or l-transposition of the great arteries with ventricular septal defect and left ventricular outflow tract obstruction
}

\author{
Jessica Sun, MBBS, ${ }^{\text {a,b }}$ Christian Brizard, MS, MD, ${ }^{\text {c,d }}$ David Winlaw, MBBS, MD, FRACS, a,b \\ Nelson Alphonso, FRCS, CTh, FRACS, MS, ${ }^{e}$ Yves d'Udekem, MD, PhD, FRACS, ${ }^{\text {,d }}$ \\ Lucas Eastaugh, MBBS, FRACP, ${ }^{\mathrm{c}, \mathrm{d}}$ Supreet Marathe, MBBS, MS, ${ }^{\mathrm{a}}$ Douglas Bell, BSC, MBBS, MS, ${ }^{\mathrm{e}}$ and \\ Julian Ayer, MBBS, PhD, FRACP ${ }^{\mathrm{a}, \mathrm{b}}$
}

\section{ABSTRACT}

Objectives: D-transposition of the great arteries and 1-transposition of the great arteries with ventricular septal defect and left ventricular outflow tract obstruction are complex biventricular congenital heart diseases for which decision-making regarding surgical strategy remains challenging. We investigated the intermediate-term outcomes of Fontan versus biventricular procedures in these patients.

Methods: We analyzed 129 patients with d-transposition of the great arteries/ventricular septal defect/left ventricular outflow tract obstruction $(n=85)$ or 1-transposition of the great arteries/ventricular septal defect/left ventricular outflow tract obstruction $(\mathrm{n}=44)$ and 2 functional ventricles from Australia who had primary surgical management (29 Fontan, 100 biventricular repair) undertaken between 1990 and 2015.

Results: Median operative age of patients was 2.9 years (range, 0.2-26.8 years). During a median follow-up of 6.2 years (range, 2 days to 25.8 years), 9 patients died after biventricular repair (3 early and 6 late deaths). One patient received a transplant 1.2 years after Fontan completion. Overall transplant-free survivals at $1,5,10$, and 15 years were $95 \%, 93 \%, 92 \%$, and $90 \%$, respectively. Overall reintervention-free survivals at $1,5,10$, and 15 years were $79 \%, 64 \%, 45 \%$, and $29 \%$ respectively. Biventricular repair tended to be associated with a higher rate of death, transplantation, or reintervention than the Fontan pathway (hazard ratio, $1.83 ; 95 \%$ confidence interval, $0.90-3.71 ; P=.10)$. Some $73 \%$ of transplant-free survivors had New York Heart Association class I. Functional status was similar between the Fontan and biventricular groups.

Conclusions: Intermediate-term outcomes were comparable between patients with d-transposition of the great arteries/ventricular septal defect/left ventricular outflow tract obstruction and patients with 1-transposition of the great arteries/ ventricular septal defect/left ventricular outflow tract obstruction. Both Fontan and biventricular pathways are associated with excellent mortality and functional outcomes. Biventricular patients have a greater risk of reintervention. The Fontan procedure is a viable option when anatomic risk factors preclude biventricular repair. (J Thorac Cardiovasc Surg 2019;158:1158-67)

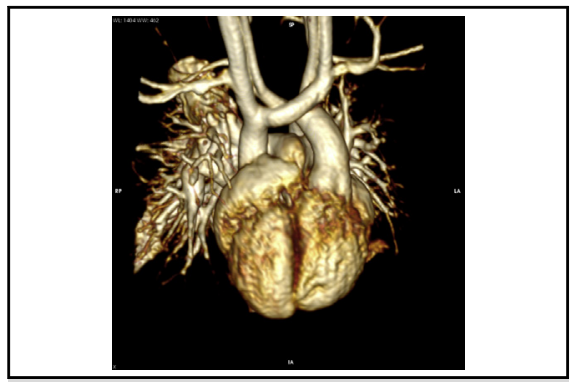

Contrast-enhanced magnetic resonance angiogram of L-TGA + VSD + LVOTO.

\section{Central Message}

In patients with D-TGA or L-TGA + VSD + LVOTO, Fontan palliation results in good medium-term survival and functional class and lower reintervention rates compared with biventricular repair.

\section{Perspective}

Decisions on the optimal surgical strategy in patients with D-TGA or L-TGA + VSD + LVOTO are challenging. This 25 -year multiinstitutional study shows equivalent mediumterm survival and functional class and lower reintervention after Fontan compared with biventricular repair. Fontan palliation may be a good long-term option for patients with anatomic features that preclude biventricular repair.

See Commentaries on pages 1168 and 1171.
From the a'The Heart Centre for Children, The Children's Hospital at Westmead, New South Wales, Australia; ${ }^{\mathrm{b}}$ The University of Sydney, Sydney, New South Wales, Australia; 'The Royal Children's Hospital, Melbourne, Victoria, Australia; ${ }^{\mathrm{d}}$ The Murdoch Children's Research Institute, Melbourne, Victoria, Australia; and ${ }^{\mathrm{e}}$ The Lady Cilento Children's Hospital, Brisbane, Queensland, Australia.

Institutional Review Board Approvals: RCH 35103B, SCHN LNR/15/SCHN/293, HREC/17/QRCH/252.
Received for publication Aug 22, 2018; revisions received April 12, 2019; accepted for publication May 3, 2019; available ahead of print July 10, 2019. Address for reprints: Julian Ayer, MBBS, PhD, FRACP, The Heart Centre for Children, The Children's Hospital at Westmead, Locked Bag 4001, Westmead, 2145, Australia (E-mail: julian.ayer@health.nsw.gov.au). $0022-5223 / \$ 36.00$

Copyright (C) 2019 by The American Association for Thoracic Surgery https://doi.org/10.1016/j.jtcvs.2019.05.061 

Abbreviations and Acronyms
$\mathrm{AV}=$ atrioventricular
BDG = bidirectional Glenn
D-TGA $=$ d-transposition of the great arteries
$\mathrm{ECC}=$ extracardiac conduit
LT $=$ lateral tunnel
L-TGA $=1$-transposition of the great arteries
LVOTO $=$ left ventricular outflow tract obstruction
NYHA $=$ New York Heart Association
PA = pulmonary artery
$\mathrm{RV} \quad=$ right ventricle
VSD $=$ ventricular septal defect
REV = Réparation a l'étage Ventriculaire.

\begin{abstract}
Scanning this $\mathrm{QR}$ code will take you to the article title page to access supplementary information.
\end{abstract}

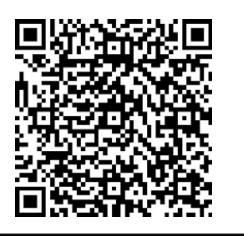

D-transposition of the great arteries (D-TGA) (atrioventricular $[\mathrm{AV}]$ concordance with ventriculo-arterial discordance) and 1-transposition of the great arteries (L-TGA) (AV discordance and ventriculo-arterial discordance) with ventricular septal defect (VSD) and left ventricular outflow tract obstruction (LVOTO) are rare but important congenital heart defects for which decision-making regarding the type of surgical repair remains challenging. The key decision centers on whether a complex intracardiac repair can be achieved allowing VSD closure such that the morphologic left ventricle acts as the systemic ventricle and the morphologic right ventricle (RV) acts as the subpulmonary ventricle. This biventricular approach must be undertaken without compromising the left ventricular outflow tract, $\mathrm{RV}$ size, conduction system, and AV valves, and with low mortality and reintervention rates.

D-TGA/VSD/LVOTO and L-TGA/VSD/LVOTO can be considered together because both lesions share some technical complexities in achieving a biventricular repair. Because these defects have 2 functional ventricles, there may be a bias toward a biventricular rather than a univentricular Fontan approach. This bias may relate to the perception of Fontan "palliation" as a circulation that will eventually fail. However, recent reports indicate that patients with complex biventricular anatomy who undergo the lateral tunnel (LT) or extracardiac conduit (ECC) Fontan procedure may have better long-term survival, lower reintervention rates, and postoperative heart block, as well as better preserved tricuspid valve function compared with those undergoing biventricular repair. ${ }^{1-4}$
In D-TGA/VSD/LVOTO, a number of biventricular approaches have been proposed, including the Rastelli (patch closure of the VSD directing blood from the left ventricle to the aorta through the VSD and insertion of an RV-topulmonary artery [PA] conduit), Réparation a l'étage Ventriculaire (REV) (resection of the conal septum, VSD enlargement, and direct reimplantation of the PA on the RV), and Nikaidoh (aortic root translocation allowing for a more anatomically aligned left ventricular outflow tract and RV-PA conduit/patch) procedures. In L-TGA/VSD/ LVOTO, 2 biventricular approaches are possible: "physiologic" repair (VSD closure and insertion of a left ventricle-PA conduit), which has largely been abandoned, and "anatomic repair," incorporating an atrial switch (usually a Senning procedure) with a Rastelli (Senning-Rastelli) or Nikaidoh (Senning-Nikaidoh).,

To date, reports of outcomes for patients with D-TGA/ VSD/LVOTO or L-TGA/VSD/LVOTO have been limited to single-center experiences and/or by small numbers with only short-term follow-up. ${ }^{1-4,6-13}$ Thus, the aim of this study was to compare longer-term outcomes following different surgical strategies in these patients, using data collected from the Australia and New Zealand Fontan Registry and 3 large pediatric cardiac units (Sydney, Melbourne, and Brisbane) and adult congenital heart disease centers across Australia. Specifically, we aimed to (1) report the indications for Fontan versus biventricular repair; (2) compare outcomes after a Fontan procedure and various types of biventricular repair; and (3) investigate predictors of adverse outcomes after a Fontan procedure or biventricular repair.

\section{MATERIALS AND METHODS}

The Sydney Children's Hospitals Network, The Royal Children's Hospital Melbourne, and Children's Health Queensland Human Research Ethics Committees approved this retrospective cohort study. Patients with D-TGA/VSD/LVOTO or L-TGA/VSD/LVOTO and 2 functional ventricles who received definitive surgical management between 1990 and 2015 were identified from the Australia and New Zealand Fontan Registry, and inpatient and outpatient records from pediatric cardiac centers in Sydney (Children's Hospital at Westmead), Melbourne (Royal Children's Hospital), and Brisbane (Prince Charles/Mater/Lady Cilento Children's Hospital), Australia. Long-term follow-up data were obtained from adult congenital heart disease clinics. This 26-year time period was chosen because it represents a relatively contemporary cohort with good mediumand long-term follow-ups.

The following information was sought: (1) patient demographics; (2) morphologic diagnosis; (3) primary procedure, age at this procedure, and center at which this procedure was undertaken; (4) prerepair procedure(s); (5) subsequent surgical reintervention(s) and age at these procedure(s); and (6) current status including whether alive or dead, or received transplant, and functional class at most recent follow-up if still alive. Patients were excluded if they had a univentricular or indeterminate morphology, or underwent an arterial switch or double switch operation (indicating no significant LVOTO).

Primary procedure was defined as the definitive corrective surgery. Reintervention was defined as any cardiac surgery after the primary procedure, excluding delayed sternal closure, revision for bleeding, or 
mediastinal infection. Early death was defined as that occurring within 30 days of the definitive procedure. Functional class was extrapolated from follow-up reports and classified using the New York Heart Association (NYHA) classification system.

Data analysis was carried out with SAS statistical software (SAS Institute Inc, Cary, NC). The primary outcomes were transplant-free survival, reintervention-free survival, and functional status. Time to death, transplantation, and reintervention were analyzed by the Kaplan-Meier method with all survival analyses truncated when less than $10 \%$ of the at-risk population remained. The proportional hazards assumption was tested for all models and was not violated in any model. Outcomes were analyzed for the whole group as well as for diagnosis and type of surgical pathway. A Cox proportional hazards model was used to determine if any of the following factors were predictors of death, transplant, or reintervention: diagnosis, type of surgical pathway, age at primary procedure, era of primary procedure $(\leq 2000$ or $>2000)$, and center where the primary procedure was performed. Differences by the type of surgical pathway were analyzed with Wilcoxon 2-sample test or a chi-square test, as appropriate.

\section{Results}

A total of 129 patients with D-TGA or L-TGA + VSD + LVOTO underwent a Fontan procedure or biventricular repair. Era $(\leq 2000$ or $>2000)$ was not associated with a significantly higher proportion of biventricular repair

TABLE 1. Patient characteristics

\begin{tabular}{|c|c|c|c|}
\hline Characteristic & $\begin{array}{c}\text { Total } \\
\text { population }\end{array}$ & Fontan & Biventricular \\
\hline No. of patients (n) & 129 & 29 & 100 \\
\hline $\operatorname{Age}^{*}(\mathrm{y}$, range $)$ & $2.9(0.2-26.8)$ & $5.4(1.4-15.7)$ & $1.8(0.2-26.8)$ \\
\hline Female (n, \%) & $43(33)$ & $13(45)$ & $30(30)$ \\
\hline $\begin{array}{l}\text { Diagnosis }(\mathrm{n}, \%) \\
\text { D-TGA/VSD/LVOTO } \\
\text { L-TGA/VSD/LVOTO }\end{array}$ & $\begin{array}{l}85(66) \\
44(34)\end{array}$ & $\begin{array}{l}15(52) \\
14(48)\end{array}$ & $\begin{array}{l}70(70) \\
30(30)\end{array}$ \\
\hline $\begin{array}{l}\text { Additional } \\
\quad \text { diagnoses (n, \%) } \\
\text { ASD } \\
\text { Straddling AV valve } \\
\text { Heterotaxy } \\
\text { Mesocardia } \\
\text { Dextrocardia } \\
\text { Other } \dagger\end{array}$ & $\begin{array}{r}11(9) \\
6(5) \\
2(2) \\
1(1) \\
6(5) \\
5(4)\end{array}$ & $\begin{array}{l}5(17) \\
3(10) \\
0(0) \\
1(3) \\
1(3) \\
2(7)\end{array}$ & $\begin{array}{l}6(6) \\
3(3) \\
2(2) \\
0(0) \\
5(5) \\
3(3)\end{array}$ \\
\hline $\begin{array}{l}\text { State of center }(\mathrm{n}, \%) \\
\text { NSW } \\
\text { VIC } \\
\text { QLD }\end{array}$ & $\begin{array}{l}54(42) \\
52(40) \\
23(18)\end{array}$ & $\begin{array}{r}14(48) \\
10(35) \\
5(17)\end{array}$ & $\begin{array}{l}40(40) \\
42(42) \\
18(18)\end{array}$ \\
\hline $\begin{array}{l}\text { Prerepair } \\
\text { procedures (n, \%) } \\
\text { BTS or central shunt } \\
\text { BAS or atrial } \\
\text { septectomy } \\
\text { BDG }\end{array}$ & $\begin{array}{l}83(64) \\
26(20)\end{array}$ & $\begin{array}{r}17(59) \\
7(24)\end{array}$ & $\begin{array}{l}66(66) \\
19(19)\end{array}$ \\
\hline
\end{tabular}

$D-T G A$, D-transposition of the great arteries; $L-T G A$, 1-transposition of the great arteries; VSD, ventricular septal defect; LVOTO, left ventricular outflow tract; ASD, Atrial septal defect; $A V$, atrioventricular; NSW, New South Wales; VIC, Victoria; $Q L D$, Queensland; BTS, Blalock-Taussig shunt; BAS, balloon atrial septostomy; $B D G$, bidirectional Glenn. *Median age at definitive repair. †Other additional diagnoses = Ebstein's anomaly (2), AV septal defect (1), total anomalous pulmonary venous drainage (1), patent ductus arteriosus (1).
$(83 \%$ vs $75 \%, P=.3)$. A total of 26 patients $(20 \%)$ had pulmonary atresia, and 103 patients $(80 \%)$ had pulmonary stenosis. A total of 29 patients underwent a Fontan procedure (15 with D-TGA/VSD/LVOTO and 14 with L-TGA/VSD/LVOTO). A total of 100 patients had a biventricular repair (70 with D-TGA/VSD/LVOTO and 30 with L-TGA/VSD/LVOTO). Over the study period (1990-2015), a further 14 patients with D-TGA or L-TGA + VSD + LVOTO did not achieve Fontan completion or biventricular repair (Table E1), with 4 patient deaths before a definitive procedure.

A total of 29 patients underwent a Fontan procedure for the following indications: multiple VSDs (5), multiple VSDs with complex anatomy (1), large VSD (6), remote VSD (4), straddling AV valve with complex anatomy (4), Ebstein's anomaly (2), borderline RV with predominant biventricular morphology (5), borderline left ventricle with predominant biventricular morphology (1), and poor RV function (1).

The patient characteristics are summarized in Table 1 . The median age at the primary procedure was 3.0 years (range, $0.2-26.8$ years). Median age at the time of biventricular repair was 1.8 years (range, $0.2-26.8$ years) and 5.4 years (range, 1.4 years-15.7 years) at the time of Fontan completion $(P<.01$ for difference). There was no association between the surgical center and the choice of surgical pathway (proportion undergoing biventricular repair in New South Wales $75 \%$, Victoria $81 \%$, and Queensland $78 \%$, $P=$.8). Six subjects had no recorded last follow-up date, and the remaining 123 subjects (84 with D-TGA/VSD/LVOTO, 39 with L-TGA/VSD/ LVOTO) were included in the analysis of transplant-free survival.

\section{Prerepair Procedures}

A total of 102 patients (79\%) had palliative prerepair procedures to increase pulmonary blood flow in the setting of pulmonary stenosis/atresia or increase intracardiac mixing in the setting of a restrictive atrial septum (Table 1). A total of 21 patients who received the Fontan (72\%) underwent an initial bidirectional Glenn (BDG) anastomosis. The remaining patients who received the Fontan had a single-stage Fontan completion. Two patients with D-TGA/VSD/LVOTO had an initial BDG that was subsequently taken down at the time of biventricular repair. As expected, a higher proportion of Fontan than biventricular repair cases had 2 or more prerepair procedures $(P=.01$, Table E2).

\section{Primary Procedures}

The types of primary procedures are summarized in Table 2 . The median age at Fontan procedure was 5.4 years (range, 1.4-15.7 years). Five patients had an LT, and 24 patients had an ECC. The median age at

TABLE 2. Types of primary procedures

\begin{tabular}{lcc}
\hline Primary procedure & D-TGA/VSD/LVOTO & L-TGA/VSD/LVOTO \\
\hline Fontan $\left(\mathrm{n}, \%^{*}\right)$ & $3(20)$ & $2(14)$ \\
LT & $12(80)$ & $12(86)$ \\
ECC & & \\
Biventricular $(\mathrm{n}, \% \dagger)$ & $34(49)$ & $0(0)$ \\
Rastelli & $18(26)$ & $0(0)$ \\
REV & $17(24)$ & $0(0)$ \\
Nikaidoh & $0(0)$ & $15(50)$ \\
Senning-Rastelli & $0(0)$ & $5(17)$ \\
Senning-Nikaidoh & $1(1)$ & $10(33)$ \\
Other &
\end{tabular}

$D$-TGA, D-transposition of the great arteries; $L-T G A$, 1-transposition of the great arteries; VSD, ventricular septal defect; $L V O T O$, left ventricular outflow tract; $L T$, lateral tunnel; $E C C$, extracardiac conduit; $R E V$, Réparation a l'étage Ventriculaire. *Percentage of that diagnostic group with that type of Fontan. †Percentage of that diagnostic group with that type of biventricular procedure. †Other $=$ "intraventricular repair" type not specified in the case of D-TGA/VSD/ LVOTO or physiologic repair in the cases of L-TGA/VSD/LVOTO. 


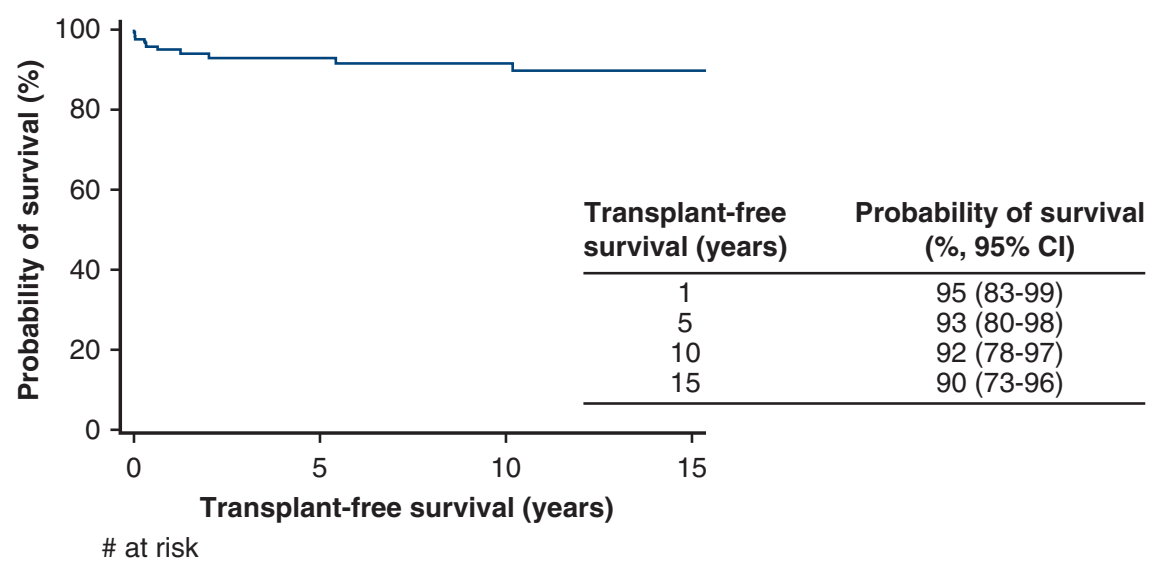

A (123)

(73)

(47)

(24)

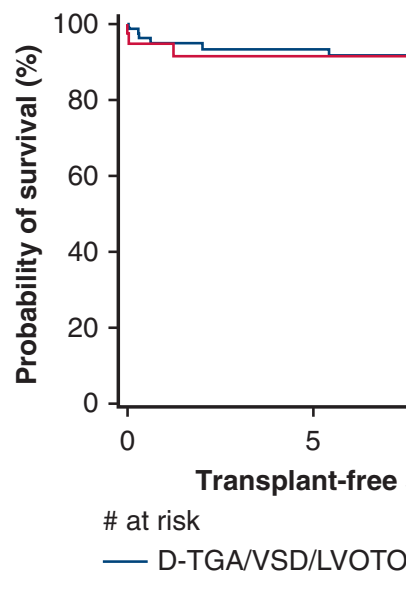

(84) (52)

D/LVOTO

(33)

(17)

B

(39)

(21)

(14)

(7)

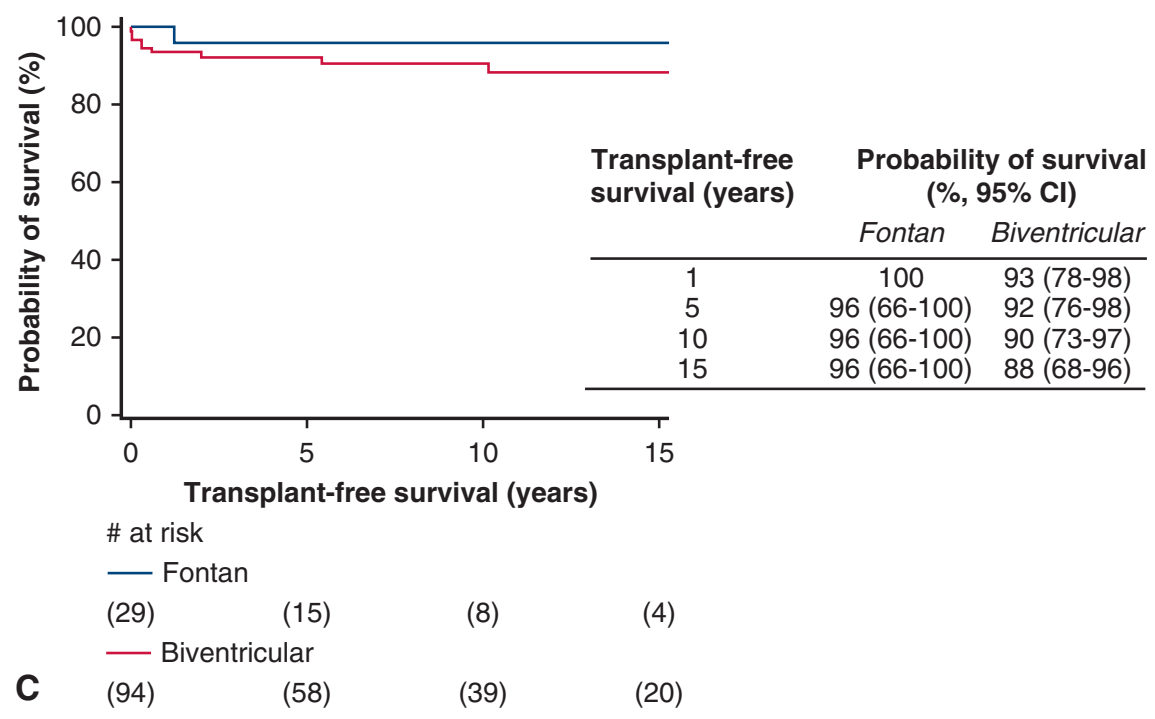

FIGURE 1. Transplant-free survival. A, For the whole group. B, According to diagnosis. C, According to type of surgical pathway. CI, Confidence interval; $D-T G A$, d-transposition of the great arteries; L-TGA, 1-transposition of the great arteries; VSD, ventricular septal defect; LVOTO, left ventricular outflow tract. 
TABLE 3. Deaths after biventricular repair

\begin{tabular}{|c|c|c|c|c|c|c|}
\hline Diagnosis & Prerepairs & $\begin{array}{c}\text { Primary } \\
\text { procedure }\end{array}$ & $\begin{array}{c}\text { Age at primary } \\
\text { procedure }(\mathbf{y})\end{array}$ & Reinterventions & $\begin{array}{c}\text { Timing of death } \\
\text { after primary } \\
\text { procedure } \\
\end{array}$ & Mode of death \\
\hline D-TGA & BT shunt & Rastelli & 1.3 & $\begin{array}{l}\text { Pacemaker } \\
\text { LVOTO relief } \\
\text { RVOTO relief } \\
\text { Pacemaker removal }\end{array}$ & $20 \mathrm{y}$ & Indeterminate \\
\hline D-TGA & TAPVD repair & Rastelli & 1.3 & None & $2 \mathrm{y}$ & Sudden cardiac \\
\hline D-TGA & $\begin{array}{l}\text { BT shunt } \\
\text { BT shunt revision } \\
\text { Central shunt }\end{array}$ & Rastelli & 2 & None & $7 \mathrm{y}$ & Sudden cardiac \\
\hline D-TGA & BAS & Rastelli & 4 & $\begin{array}{l}\text { VSD closure } \\
\text { RVOTO relief }\end{array}$ & $23 \mathrm{y}$ & Sudden cardiac \\
\hline D-TGA & BT shunt & REV & 2 & RVOTO relief & $11 \mathrm{~d}$ & Sudden cardiac \\
\hline D-TGA & BT shunt & REV & 8 & None & $3 \mathrm{mo}$ & Indeterminate \\
\hline L-TGA & None & Senning Rastelli & 4 & None & $2 \mathrm{~d}$ & Postoperative cardiac arrest \\
\hline L-TGA & BT shunt & Senning Rastelli & 8 & $\begin{array}{l}\text { Emergency surgery to control } \\
\text { post-operative aero-digestive } \\
\text { hemorrhage }\end{array}$ & $8 \mathrm{~d}$ & $\begin{array}{c}\text { Cardiac arrest after aero- } \\
\text { digestive hemorrhage }\end{array}$ \\
\hline D-TGA & None & Nikaidoh & 11 & None & $4 \mathrm{mo}$ & Thromboembolic event \\
\hline
\end{tabular}

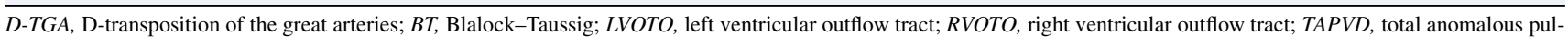
monary venous drainage; $B A S$, balloon atrial septostomy; VSD, ventricular septal defect; $R E V$, Réparation a l'étage Ventriculaire; $L-T G A$, l-transposition of the great arteries.

biventricular repair was 1.8 years (range, $0.2-26.8$ years). The main biventricular procedures performed on patients with D-TGA/VSD/LVOTO were Rastelli (34/70, 49\%, 1 with BDG), REV (18/70, 26\%), and Nikaidoh (17/ $70,24 \%$ ). Patients with L-TGA/VSD/LVOTO who underwent a biventricular repair had a Senning-Rastelli $(15 / 30,50 \%$, 1 with hemi-Mustard), Senning-Nikaidoh $(5 / 30,17 \%)$, or physiologic repair $(9 / 30,30 \%)$.

\section{Follow-up and Freedom From Death or Transplant}

Patients were followed for a median of 6.2 years (range, 2 days to 24.6 years). Median follow-up of those who received the Fontan was 5.4 years (range, 0.1-22.6 years) and 7.3 years (range, $0-25.8$ years) after biventricular repair. At 1, 5, 10, and 15 years, freedom from death or transplant for the whole group was $95 \%, 93 \%, 92 \%$, and $90 \%$, respectively (Figure 1, $A$ ). Nine patients died over the follow-up period; all had undergone a biventricular repair (Table 3 ). Three of these were early postoperative deaths ( $<30$ days). The mode of 2 late deaths was not ascertainable, whereas the remaining late deaths were sudden presumed cardiac (3) or related to thromboembolism (1). Additionally, 1 patient with L-TGA/ VSD/LVOTO received a transplant 1.2 years after having a Fontan procedure.

Transplant-free survival at 15 years was comparable between the DTGA/VSD/LVOTO and L-TGA/VSD/LVOTO groups ( $92 \%$ and $85 \%$, respectively) (Figure 1, B). The 15-year freedom from death or transplant was high and similar in Fontan $(96 \%)$ and biventricular $(88 \%)$ groups (Figure 1, C).

\section{Reinterventions}

The types of reinterventions are summarized in Tables 4 and 5 . For the whole group, freedom from reintervention was $92 \%$ at 1 month, $79 \%$ at 1 year, $64 \%$ at 5 years, $45 \%$ at 10 years, and $29 \%$ at 15 years (Figure 2, $A$ ). Freedom from reintervention in D-TGA/VSD/LVOTO was similar to L-TGA/VSD/LVOTO (Figure 2, B). However, freedom from reintervention was lower in the biventricular group compared with the Fontan group, with 15 -year reintervention-free survival being $25 \%$ and $47 \%$, respectively (Figure 2, C).

Reinterventions were classed as expected and unexpected (Tables 4 and 5). Expected reinterventions were RVOTO relief including RV-PA conduit replacement after Rastelli (12/34, 35\%), Senning-Rastelli (3/15, $20 \%$ ), and Nikaidoh $(3 / 17,18 \%)$ procedures; LV-PA conduit replacement after a physiologic repair for L-TGA $(4 / 9,44 \%)$; or fenestration closure after a Fontan procedure $(1 / 29,3 \%)$. Unexpected reinterventions occurred in 8 patients $(28 \%)$ receiving the Fontan and 40 biventricular patients $(40 \%)$. These included LVOTO relief after a Rastelli $(4 / 34,12 \%)$ or REV (3/18, $17 \%)$; RVOTO relief after REV (5/18, 28\%), pacemaker insertion (3/29 Fontan, 12/100 biventricular), AV valve repair (5), PA plasty (8), and other reinterventions, including (a) after Fontan completion - VSD enlargement

TABLE 4. Expected versus unexpected reinterventions

\begin{tabular}{|c|c|c|c|c|c|c|c|}
\hline \multirow[b]{2}{*}{ Reintervention } & \multirow[b]{2}{*}{$\begin{array}{c}\text { Fontan } \\
(\mathbf{n}, \%)\end{array}$} & \multicolumn{6}{|c|}{ Biventricular } \\
\hline & & $\begin{array}{l}\text { Rastelli } \\
(n, \%)\end{array}$ & $\begin{array}{c}\text { Nikaidoh } \\
(n, \%)\end{array}$ & $\begin{array}{c}\text { REV } \\
(n, \%)\end{array}$ & $\begin{array}{c}\text { Senning-Rastelli } \\
(\mathbf{n}, \%)\end{array}$ & $\begin{array}{c}\text { Senning-Nikaidoh } \\
(\mathrm{n}, \%)\end{array}$ & $\begin{array}{c}\text { Other } \\
(\mathbf{n}, \%) *\end{array}$ \\
\hline Any reintervention & $9(31)$ & $20(59)$ & $6(35)$ & $9(50)$ & $9(60)$ & $3(60)$ & $6(55)$ \\
\hline Any expected reintervention & $1(3)$ & $12(35)$ & $3(18)$ & $0(0)$ & $3(20)$ & $0(0)$ & $4(36)$ \\
\hline Any unexpected reintervention & $8(28)$ & $13(38)$ & $4(24)$ & $9(50)$ & $6(40)$ & $3(60)$ & $5(45)$ \\
\hline
\end{tabular}

$R E V$, Réparation a l'étage Ventriculaire. *Other primary procedure = physiologic repair or "intraventricular repair" type not specified. 
TABLE 5. Types of reinterventions

\begin{tabular}{|c|c|c|c|c|c|c|c|}
\hline \multirow[b]{2}{*}{ Reintervention } & \multirow[b]{2}{*}{$\begin{array}{r}\text { Fontan } \\
(\mathbf{n}, \%)\end{array}$} & \multicolumn{6}{|c|}{ Biventricular } \\
\hline & & $\begin{array}{c}\text { Rastelli } \\
(\mathbf{n}, \%)\end{array}$ & $\begin{array}{c}\text { Nikaidoh } \\
(\mathbf{n}, \%)\end{array}$ & $\begin{array}{l}\text { REV } \\
(\mathbf{n}, \%)\end{array}$ & $\begin{array}{c}\text { Senning-Rastelli } \\
(\mathrm{n}, \%)\end{array}$ & $\begin{array}{c}\text { Senning-Nikaidoh } \\
(\mathbf{n}, \%)\end{array}$ & $\begin{array}{l}\text { Other } \\
(\mathbf{n}, \%) *\end{array}$ \\
\hline Any reintervention & $9(31)$ & $20(59)$ & $6(35)$ & $9(50)$ & $9(60)$ & $3(60)$ & $6(55)$ \\
\hline Any expected reintervention & $1(3)$ & $12(35)$ & $3(18)$ & $0(0)$ & $3(20)$ & $0(0)$ & $4(36)$ \\
\hline RVOTO relief $\dagger$ & & $12(35)$ & $3(18)$ & & $3(20)$ & & \\
\hline LV-PA conduit change/repair & & & & & & & $4(36)$ \\
\hline Fenestration closure after Fontan & $1(3)$ & & & & & & \\
\hline Any unexpected reintervention & $8(28)$ & $13(38)$ & $4(24)$ & $9(50)$ & $6(40)$ & $3(60)$ & $5(45)$ \\
\hline LVOTO relief after Rastelli/REV & & $4(12)$ & & $3(17)$ & $1(7)$ & & \\
\hline RVOTO relief after REV & & & & $5(28)$ & & & \\
\hline Pacemaker & $3(10)$ & $2(6)$ & & $1(6)$ & $3(20)$ & $2(40)$ & $4(36)$ \\
\hline AV valve repair & $1(3)$ & & $1(6)$ & $1(6)$ & & & $2(18)$ \\
\hline PA plasty/stent & $2(7)$ & $2(6)$ & $1(6)$ & $2(11)$ & $1(7)$ & & \\
\hline Other $\ddagger$ & $9(31)$ & $15(44)$ & $2(12)$ & $2(11)$ & $1(7)$ & $2(40)$ & $4(36)$ \\
\hline \multicolumn{8}{|l|}{ No. of reinterventions per patient } \\
\hline 1 & $5(17)$ & $14(41)$ & $6(35)$ & $7(39)$ & $9(60)$ & $2(40)$ & $4(36)$ \\
\hline$>1$ & $4(14)$ & $6(18)$ & $0(0)$ & $2(11)$ & $0(0)$ & $1(20)$ & $2(18)$ \\
\hline
\end{tabular}

$R E V$, Réparation a l'étage Ventriculaire; RVOTO, right ventricular outflow tract obstruction; $L V$ - $P A$, left ventricle-pulmonary artery; $L V O T O$, left ventricular outflow tract obstruction; $A V$, atrioventricular; $P A$, pulmonary artery. *Other primary procedure = physiologic repair or "intraventricular repair" type not specified. $\dagger$ Includes RV-PA conduit change. $\ddagger$ Other unexpected reintervention, see text.

(2), inferior vena cava/superior vena cava reconstruction (1), ligation of a left superior vena cava (1), conversion to Rastelli (1), and Fontan takedown and transplantation (1); (b) after Rastelli - VSD closure (4), ASD closure (1), conversion to REV (1), PA repair (6); (c) after Nakaidoh-aortic valve repair (1); (d) after REV - VSD closure (1), pulmonary valve replacement (1); (e) after Senning-Nikaidoh-revision of atrial baffle (2); and (f) after physiologic repair - ASD closure (1), upgrade to implantable cardioverter defibrillator (1). One patient undergoing the Fontan was subsequently converted to a biventricular pathway with a Rastelli procedure. On reassessment, this patient was thought to have anatomy that was more suited to biventricular repair with normal-sized AV valves, balanced ventricles, and a high muscular VSD. Furthermore, 1 patient who initially had a Rastelli procedure was converted to a REV procedure 2.8 years later because of progressive intraventricular baffle obstruction secondary to infundibular restriction.

Expected reinterventions were more likely to occur after biventricular rather than univentricular repair $(P=.02)$. A greater proportion of biventricular patients required unexpected reinterventions (41\% vs $28 \%$ ), although this did not achieve significance $(P=.2)$.

\section{Predictors of Death, Transplant, or Reintervention}

The risk factors of adverse outcomes are summarized in Table 6. A biventricular strategy was associated with a greater risk for death, transplant, or reintervention (hazard ratio, 1.9, 95\% confidence interval, 0.88-4.01), although this did not reach significance $(P=.10)$. The SenningNikaidoh procedure had the most substantial hazard in comparison with Fontan completion $(P=.01)$, although few subjects had this operation undertaken. Diagnosis, age, era, and surgical center were not found to be significant predictors of such outcomes.

\section{Functional Outcome}

Overall, the majority of the transplant-free survivors $(87 / 119,73 \%)$ were NYHA class I (Table 7). The proportion of patients in each functional class was similar by diagnosis. Likewise, functional class was comparable between the Fontan and biventricular groups.

\section{DISCUSSION}

The principle findings in our study were (1) comparable survival, reintervention rates, and functional status in subjects with D-TGA/VSD/LVOTO or L-TGA/VSD/LVOTO; (2) a trend to higher mortality and reintervention rates in biventricular versus Fontan cases; and (3) equivalent functional status in those who had biventricular and Fontan strategies. Our data represent one of the largest series of such patients and include the contemporary experience of the 3 main cardiac surgical centers in Australia. The additional strengths of our data include good intermediate follow-up and a description of outcomes by morphologic diagnosis rather than just by primary procedure, which may be helpful for counseling at all stages of life.

\section{Outcomes According to Type of Surgical Pathway}

Biventricular repair is often strived for in patients with complex congenital heart disease and 2 adequately sized ventricles, assuming that this will lead to better long-term outcomes. Noting that all deaths in our study occurred in the biventricular group, we can at least say that intermediate survival was no worse after Fontan completion than after biventricular repair. We also observed that patients who underwent the Fontan procedure had higher freedom from reintervention and lower incidences of expected and unexpected reinterventions. There was a trend toward biventricular repair being associated with increased risk for death, transplant, or reintervention. Our findings are consistent with those of previous studies, which have shown 


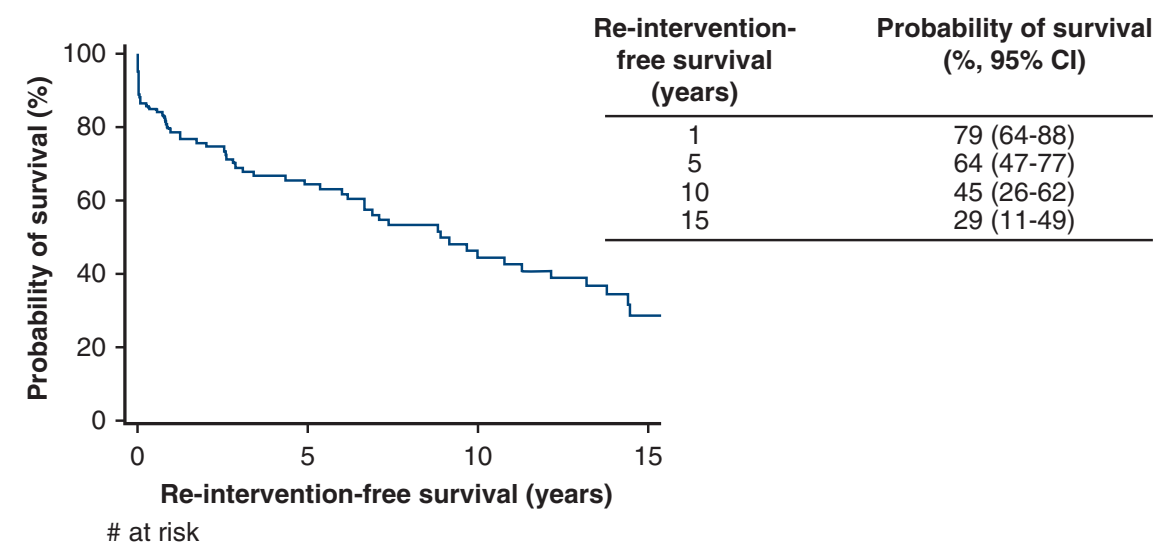
A
(128)
(53)
(24)
(10)

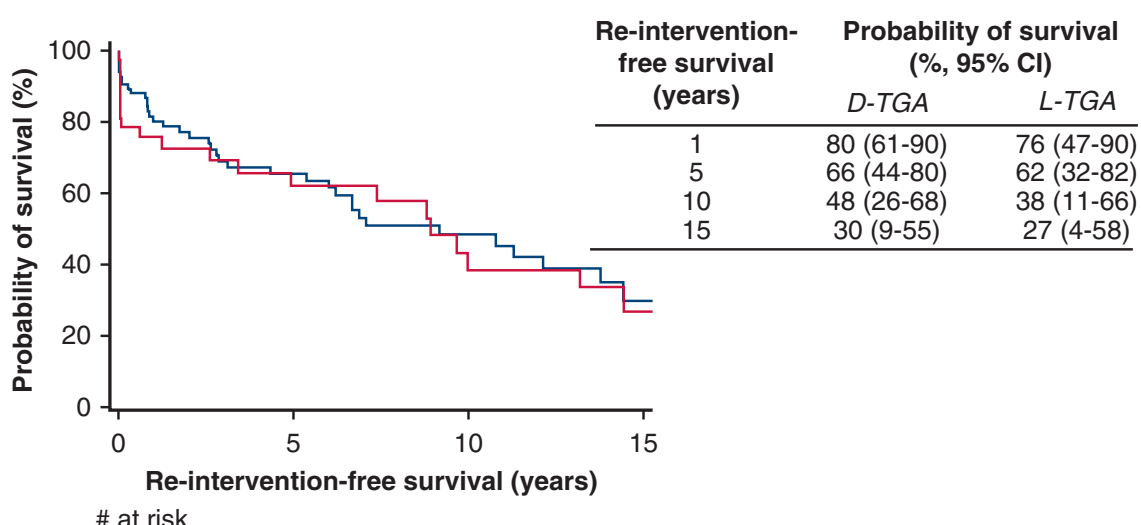

\# at risk

— D-TGA/VSD/LVOTO
(85)
(37)
(16)
(6)

B

(43)

(16)

(8)

(4)

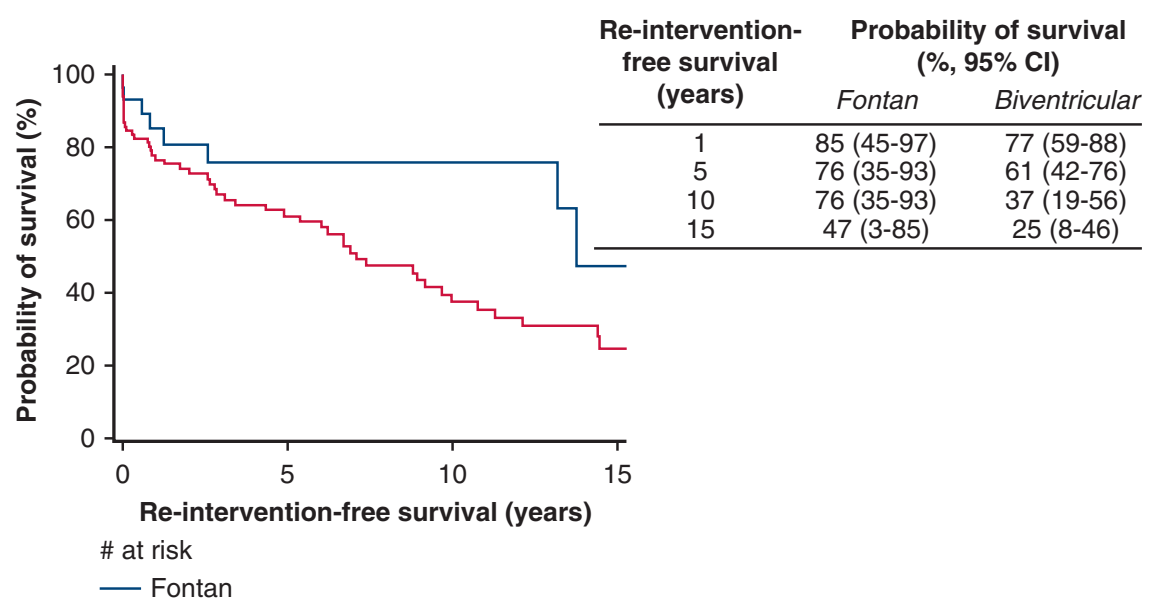
(29)
(12)
(6)
(2)

C $\quad$ Biventricular

(18)

(80)

FIGURE 2. Reintervention-free survival. A, For the whole group. B, According to diagnosis. C, According to type of surgical pathway. $C I$, Confidence interval; D-TGA, d-transposition of the great arteries; $L-T G A$, 1-transposition of the great arteries; VSD, ventricular septal defect; LVOTO, left ventricular outflow tract. 
TABLE 6. Risk factors for reintervention, death, or transplant

\begin{tabular}{llc}
\hline \multicolumn{1}{c}{ Risk factor } & HR $(\mathbf{9 5} \%$ CI) & $\boldsymbol{P}$ value \\
\hline Diagnosis & $1.13(0.67-1.90)$ & .66 \\
Type of surgical pathway & $1.83(0.90-3.71)$ & .10 \\
$\quad$ (biventricular vs Fontan) & & \\
Type of primary procedure & & \\
$\quad$ (reference level Fontan) & & .18 \\
Rastelli & $1.71(0.78-3.75)$ & .21 \\
Nikaidoh & $1.95(0.69-5.53)$ & .16 \\
REV procedure & $1.94(0.77-4.90)$ & .17 \\
Senning-Rastelli & $1.90(0.75-4.80)$ & .01 \\
Senning-Nikaidoh & $5.51(1.45-20.93)$ & .60 \\
Other & $1.34(0.45-4.00)$ & .83 \\
Age at primary procedure & $1.01(0.94-1.09)$ & .46 \\
Era of primary procedure & $1.24(0.71-2.17)$ & \\
$\quad>2000$ vs $\leq 2000)$ & & .12 \\
Centre of primary procedure & & .04 \\
$\quad$ (reference level CHW) & & .38 \\
RCH & $1.80(1.02-3.20)$ & \\
LCCH & $1.39(0.66-2.92)$ & \\
\hline
\end{tabular}

$H R$, Hazard ratio; $C I$, confidence interval; $C H W$, children's Hospital at Westmead; $R C H$, Royal Children's Hospital; LCCH, Mater Hospital/Prince Charles Hospital/ Lady Cilento.

equivalent or lower mortality and reintervention rates in patients with D-TGA/VSD/LVOTO or L-TGA/VSD/LVOTO undergoing a Fontan procedure compared with biventricular repair. ${ }^{1,3,14}$ Good functional outcomes were found in both Fontan and biventricular groups in our study, with $97 \%$ and $96 \%$ in NYHA class I/II at most recent followup, respectively. However, no univentricular patients had NYHA class III/IV, whereas 2 biventricular repair patients had NYHA class III/IV.

Our data suggest that a univentricular strategy, in patients in whom a biventricular repair is not possible, results in good intermediate-term outcomes. The majority of patients who underwent the Fontan procedures in our study had an ECC, and a number of recent reports suggest better outcomes after ECC compared particularly with atriopulmonary Fontan. For example, d'Udekem and colleagues ${ }^{15}$ in a report from the Australia and New Zealand Fontan
Registry of more than 1000 patients undergoing the Fontan-the majority of whom had univentricular morphology-described 10-year survival of $89 \%$ for atriopulmonary Fontan and $97 \%$ for LT and ECC. Survival to 20 years was $90 \%$ for LT, and at 25 years was $76 \%$ for atriopulmonary Fontan. In our current study of patients with D-TGA/VSD/LVOTO or L-TGA/VSD/LVOTO, freedom from death or transplantation was comparable at 15 years in both the Fontan and biventricular groups to that documented in LT and ECC Fontan groups from the Australia and New Zealand Fontan Registry.

Although the Fontan procedure is associated with excellent medium-term survival, it can result in long-term morbidity because of the development of arrhythmia and thromboembolism. ${ }^{16}$ Moreover, univentricular physiology may be associated with progressive ventricular dysfunction, lower cardiac output, and ultimately decreased exercise capacity. ${ }^{17}$ Some reports have demonstrated a steep decline in survival of patients who underwent the Fontan after 20 years because of such late complications. ${ }^{18,19}$ Furthermore, the prevalence of complications relating to lymphatic disorders, including protein-losing enteropathy, plastic bronchitis, and Fontan-associated liver disease, may be more common than previously recognized. ${ }^{20}$ We have not captured data in relation to objective measures of exercise capacity or quality of life, both of which may be better preserved after biventricular repair. Nonetheless, in our study of patients with "biventricular" morphology, only 2 of the 29 Fontan cases had Fontan "failure." One was converted to a Rastelli 14 years post-Fontan, and 1 required relatively early transplantation at 1 year post-Fontan.

\section{Outcomes According to Diagnosis}

Despite the different anatomy, patients with D-TGA/ VSD/LVOTO and L-TGA/VSD/LVOTO share some similarities in terms of the technical considerations in achieving a complex intracardiac repair. However, a greater propensity toward the development of heart block is inherent in patients with L-TGA. In our study, these 2 diagnostic groups were comparable in all outcome measures; analysis showed that morphologic diagnosis was not a significant predictor of mortality, transplant, or reintervention.

TABLE 7. Functional class of transplant-free survivors at most recent follow-up

\begin{tabular}{|c|c|c|c|c|c|}
\hline Diagnosis or surgical pathway & NYHA I & NYHA II & NYHA III & NYHA IV & Unknown \\
\hline \multicolumn{6}{|l|}{ Diagnosis $(\mathrm{n}, \% *$ ) } \\
\hline D-TGA/VSD/LVOTO & $59(76)$ & $12(15)$ & $1(1)$ & $0(0)$ & $6(8)$ \\
\hline L-TGA/VSD/LVOTO & $28(68)$ & $6(15)$ & $0(0)$ & $1(2)$ & $6(15)$ \\
\hline \multicolumn{6}{|l|}{ Surgical pathway $(\mathrm{n}, \% \dagger)$} \\
\hline Fontan $(\mathrm{n}, \%)$ & $24(86)$ & $3(11)$ & $0(0)$ & $0(0)$ & $1(3)$ \\
\hline Biventricular (n, \%) & $63(69)$ & $15(17)$ & $1(1)$ & $1(1)$ & $11(12)$ \\
\hline
\end{tabular}

NYHA, New York Heart Association; D-TGA/VSD/LVOTO, d-transposition of the great arteries/ventricular septal defect/left ventricular outflow tract; L-TGA/VSD/LVOTO, 1-transposition of the great arteries/ventricular septal defect/left ventricular outflow tract obstruction. *Percentage of that diagnostic group in that NYHA class. $\dagger$ Percentage of the surgical group in that NYHA class. 
In the D-TGA/VSD/LVOTO cohort, we have shown high rates of reintervention after the Rastelli procedure, principally the expected reintervention to relieve RV-PA dysfunction. Furthermore, 44\% (4/9) of deaths in this study occurred after the Rastelli procedure. Our findings align with other studies that have found suboptimal long-term outcomes after the Rastelli procedure and call into question the role of this operation in patients with D-TGA/VSD/ LVOTO. $^{2,11}$ We have demonstrated lower but not insignificant rates of RVOTO relief after the Nikaidoh and REV procedures. The reintervention rates for residual LVOTO were comparable between Rastelli and REV cases. However, previous studies have observed lower LVOTO reintervention rates in REV versus Rastelli cases. ${ }^{10,11}$ This discrepancy could be explained by the small number of patients in each surgical subgroup of our study. Contrastingly, no patients receiving the Nikaidoh required LVOTO relief during the study period, which is consistent with previous reports. ${ }^{7,9}$

In patients with L-TGA/VSD/LVOTO, previous studies have demonstrated disappointing long-term outcomes after physiologic repair, because maintaining the RV as the systemic ventricle can result in heart failure, tricuspid valve regurgitation with resultant repair or replacement, AV block, and other arrhythmias. ${ }^{1,21}$ Although only 10 patients in our study had a physiologic repair, our study suggested similar poor outcomes; $4(40 \%)$ developed arrhythmias or $\mathrm{AV}$ block requiring pacemaker insertion, and $3(30 \%)$ had suboptimal functional outcomes (2 in NYHA class II and 1 in NYHA class IV). By contrast, the majority of patients who had anatomic repair were in NYHA class I. We also observed a lower incidence of heart block necessitating pacemaker insertion in patients who had anatomic repair, consistent with the findings of the meta-analysis by Alghamdi and colleagues ${ }^{5}$ of 11 studies involving 124 patients with congenitally corrected transposition of the great arteries.

\section{Study Limitations}

Our study involved retrospective collection and analysis of data from preexisting records. We relied on the treating physicians to have coded diagnoses correctly. Functional class was also extrapolated from records of symptoms and exercise limitation made by physicians at the last clinical follow-up and is thus a subjective assessment. Differences in objective measures of exercise and ventricular function between those who underwent the Fontan and those who underwent biventricular repair were not determined in this study. Our functional classification may not accurately reflect exercise capacity, and it may be expected that a biventricular repair will allow greater exercise tolerance. Follow-up beyond 10 to 15 years was limited, particularly for patients receiving the Fontan and patients with L-TGA/VSD/LVOTO, for whom there were smaller subject numbers. Caution should be exercised in interpreting outcomes beyond this time period for both Fontan and biventricular groups because other reports demonstrate reduced survival 20 years after Fontan and a risk of morphologic left ventricular dysfunction after complex biventricular repair. Additionally, given the paucity of deaths that occurred during this study, predictors of mortality alone were unable to be determined. We thus assessed the effect of various factors on both death and reintervention combined. Future multi-institutional studies with larger sample sizes are warranted to evaluate predictors of adverse outcomes.

Our study examined outcomes after biventricular repair or Fontan completion and thus did not account for adverse patient outcomes between birth and the definitive procedure. In a retrospective study such as ours, it is not possible to ascertain whether patients are on a "biventricular" or "univentricular" pathway at the time of diagnosis. Furthermore prior palliative procedures, including a BDG, do not clearly define patients as following a particular pathway. However, there were a relatively small number of patients (4) who died before a definitive procedure, and we are thus confident that our study reflects the experience of patients with these diagnoses over the study period.

\section{CONCLUSIONS}

In patients with the rare and complex diagnoses of D-TGA or L-TGA + VSD + LVOTO, biventricular and Fontan strategies appear to result in comparable mediumterm survival and functional class. Reintervention rates are higher after biventricular repair, particularly expected reinterventions such as RV-PA conduit replacement. Although our data reflect only medium-term follow-up, they suggest that Fontan "palliation" may be considered a good long-term option for patients with anatomic features that preclude biventricular circulation.

\section{Conflict of Interest Statement}

Authors have nothing to disclose with regard to commercial support.

The authors thank Liz Barnes from the Kids Research Institute The Children's Hospital at Westmead and the Australian and New Zealand Fontan Registry Research team at Murdoch Children's Research Institute. We also thank the clinical staff at all centers who cared for these patients.

\section{References}

1. Hraska V, Duncan BW, Mayer JE Jr, Freed M, del Nido PJ, Jonas RA. Long-term outcome of surgically treated patients with corrected transposition of the great arteries. J Thorac Cardiovasc Surg. 2005;129:182-91.

2. Kreutzer C, De Vive J, Oppido G, Kreutzer J, Gauvreau K, Freed M, et al. Twenty-five-year experience with Rastelli repair for transposition of the great arteries. J Thorac Cardiovasc Surg. 2000;120:211-23.

3. Shin'oka T, Kurosawa H, Imai Y, Aoki M, Ishiyama M, Sakamoto T, et al. Outcomes of definitive surgical repair for congenitally corrected transposition of the 
great arteries or double outlet right ventricle with discordant atrioventricular connections: risk analyses in 189 patients. J Thorac Cardiovasc Surg. 2007;133: 1318-28. 1328.e1311-14.

4. Weyand K, Haun C, Blaschczok H, Goetz-Toussaint N, Photiadis J, Sinzobahamvya N, et al. Surgical treatment of transposition of great arteries with ventricular septal defect and left ventricular outflow tract obstruction: midterm results. World J Pediatr Congenit Heart Surg. 2010;1:163-9.

5. Alghamdi AA, McCrindle BW, Van Arsdell GS. Physiologic versus anatomic repair of congenitally corrected transposition of the great arteries: metaanalysis of individual patient data. Ann Thorac Surg. 2006;81:1529-35.

6. Hoashi T, Kagisaki K, Miyazaki A, Kurosaki K, Shiraishi I, Yagihara T, et al. Anatomic repair for corrected transposition with left ventricular outflow tract obstruction. Ann Thorac Surg. 2013;96:611-20.

7. Yeh T Jr, Ramaciotti C, Leonard SR, Roy L, Nikaidoh H. The aortic translocation (Nikaidoh) procedure: midterm results superior to the Rastelli procedure. $J$ Thorac Cardiovasc Surg. 2007;133:461-9.

8. Murtuza B, Barron DJ, Stumper O, Stickley J, Eaton D, Jones TJ, et al. Anatomic repair for congenitally corrected transposition of the great arteries: a singleinstitution 19-year experience. J Thorac Cardiovasc Surg. 2011;142: 1348-57.e1341.

9. Morell VO, Jacobs JP, Quintessenza JA. Aortic translocation in the management of transposition of the great arteries with ventricular septal defect and pulmonary stenosis: results and follow-up. Ann Thorac Surg. 2005;79:2089-92; discussion 2092-3.

10. Lee JR, Lim HG, Kim YJ, Rho JR, Bae EJ, Noh CI, et al. Repair of transposition of the great arteries, ventricular septal defect and left ventricular outflow tract obstruction. Eur J Cardiothorac Surg. 2004;25:735-41.

11. Hazekamp MG, Gomez AA, Koolbergen DR, Hraska V, Metras DR, Mattila IP, et al. Surgery for transposition of the great arteries, ventricular septal defect and left ventricular outflow tract obstruction: European Congenital Heart Surgeons Association multicentre study. Eur J Cardiothorac Surg. 2010;38:699-706.

12. Brizard CP, Lee A, Zannino D, Davis AM, Fricke TA, d'Udekem Y, et al. Longterm results of anatomic correction for congenitally corrected transposition of the great arteries: a 19-year experience. J Thorac Cardiovasc Surg. 2017;154: 256-65.e254.
13. Bierbach B, Arenz C, Suchowerskyj P, Schroth S, Blaschczok J, Asfour B et al. Current mid-term outcome with an integrated surgical strategy for correction of d-transposition of the great arteries with ventricular septal defect and left ventricular outflow tract obstruction. Eur J Cardiothorac Surg. 2016 50:617-25.

14. Horer J, Schreiber C, Krane S, Prodan Z, Cleuziou J, Vogt M, et al. Outcome after surgical repair/palliation of congenitally corrected transposition of the great arteries. Thorac Cardiovasc Surg. 2008;56:391-7.

15. d'Udekem Y, Iyengar AJ, Galati JC, Forsdick V, Weintraub RG, Wheaton GR, et al. Redefining expectations of long-term survival after the Fontan procedure: twenty-five years of follow-up from the entire population of Australia and New Zealand. Circulation. 2014;130:S32-8.

16. Carins TA, Shi WY, Iyengar AJ, Nisbet A, Forsdick V, Zannino D, et al. Longterm outcomes after first-onset arrhythmia in Fontan physiology. J Thorac Cardiovasc Surg. 2016;152:1355-63.e1351.

17. Atz AM, Zak V, Mahony L, Uzark K, D'Agincourt N, Goldberg DJ, et al. Longitudinal outcomes of patients with single ventricle after the Fontan procedure. $J$ Am Coll Cardiol. 2017;69:2735-44.

18. Pundi KN, Johnson JN, Dearani JA, Pundi KN, Li Z, Hinck CA, et al. 40-year follow-up after the Fontan operation: long-term outcomes of 1,052 patients. $J$ Am Coll Cardiol. 2015;66:1700-10.

19. Downing TE, Allen KY, Glatz AC, Rogers LS, Ravishankar C, Rychik J, et al. Long-term survival after the Fontan operation: twenty years of experience at a single center. J Thorac Cardiovasc Surg. 2017;154:243-53.e242.

20. Caruthers RL, Kempa M, Loo A, Gulbransen E, Kelly E, Erickson SR, et al. Demographic characteristics and estimated prevalence of Fontan-associated plastic bronchitis. Pediatr Cardiol. 2013;34:256-61.

21. Graham TP Jr, Bernard YD, Mellen BG, Celermajer D, Baumgartner H, Cetta F, et al. Long-term outcome in congenitally corrected transposition of the great arteries: a multi-institutional study. J Am Coll Cardiol. 2000;36:255-61.

Key Words: transposition of the great arteries, ventricular septal defect, left ventricular outflow tract obstruction, Fontan, biventricular repair 
TABLE E1. Patients with d-transposition of the great arteries/ventricular septal defect/left ventricular outflow tract or l-transposition of the great arteries/ventricular septal defect/left ventricular outflow tract/ventricular septal defect/left ventricular outflow tract obstruction who did not achieve biventricular repair or Fontan completion by 2015

\begin{tabular}{|c|c|c|c|c|c|c|c|}
\hline & \multirow[b]{2}{*}{ Diagnosis } & \multicolumn{3}{|c|}{ Interventions } & \multirow{2}{*}{$\begin{array}{l}\text { Year of } \\
\text { birth }\end{array}$} & \multirow{2}{*}{$\begin{array}{c}\text { Age at } \\
\text { last follow-up }\end{array}$} & \multirow[b]{2}{*}{ Reason for not reaching definitive repair } \\
\hline & & $\overline{\mathbf{A S} / \mathbf{B A S}}$ & BTS & BDG & & & \\
\hline 1 & L-TGA/VSD/LVOTO & & $\mathrm{Y}$ & & 1992 & $17.0 \mathrm{y}$ & Died - indeterminate cause \\
\hline 2 & D-TGA/VSD/LVOTO & $\mathrm{Y}$ & $\mathrm{Y}$ & & 1997 & $18 \mathrm{~d}$ & Died secondary to sepsis \\
\hline 3 & D-TGA/VSD/LVOTO & & & Y & 1998 & $18.9 \mathrm{y}$ & $\begin{array}{l}\text { Unsuitable for biventricular repair. Fontan not } \\
\text { completed because of small pulmonary } \\
\text { arteries. }\end{array}$ \\
\hline 4 & D-TGA/VSD/LVOTO & $\mathrm{Y}$ & $\mathrm{Y}$ & & 2001 & $8 \mathrm{~d}$ & Lost to follow-up \\
\hline 5 & L-TGA/VSD/LVOTO & $\mathrm{Y}$ & & & 2005 & $4.5 \mathrm{mo}$ & Died - indeterminate cause \\
\hline 6 & L-TGA/VSD/LVOTO & & $\mathrm{Y}$ & & 2001 & $2.3 \mathrm{y}$ & Died - indeterminate cause \\
\hline 7 & D-TGA/VSD/LVOTO & & $\mathrm{Y}$ & Y & 2006 & $9.6 \mathrm{y}$ & $\begin{array}{l}\text { Fontan not achieved because of situs inversus, } \\
\text { mitral valve dysplasia, and pulmonary } \\
\text { hemorrhages. VSD not suitable for } \\
\text { biventricular repair. }\end{array}$ \\
\hline 8 & D-TGA/VSD/LVOTO & $\mathrm{Y}$ & & $\mathrm{Y}$ & 2008 & $4.7 \mathrm{y}$ & $\begin{array}{l}\text { VSD location not suitable for biventricular repair. } \\
\text { Lost to follow-up. }\end{array}$ \\
\hline 9 & D-TGA/VSD/LVOTO & $\mathrm{Y}$ & & $\mathrm{Y}$ & 2011 & $2.5 \mathrm{y}$ & $\begin{array}{l}\text { Straddling tricuspid valve with common } \\
\text { subvalvar apparatus with mitral valve, VSD } \\
\text { location not suitable for biventricular repair. } \\
\text { Lost to follow-up }\end{array}$ \\
\hline 10 & D-TGA/VSD/LVOTO & Y & $\mathrm{Y}$ & & 2011 & $4.0 \mathrm{y}$ & $\begin{array}{l}\text { Awaiting definitive repair at the time of study } \\
\text { censoring }\end{array}$ \\
\hline 11 & L-TGA/VSD/LVOTO & & $\mathrm{Y}$ & & 2012 & $2.5 \mathrm{y}$ & $\begin{array}{l}\text { Awaiting definitive repair at the time of study } \\
\text { censoring }\end{array}$ \\
\hline 12 & L-TGA/VSD/LVOTO & & & $\mathrm{Y}$ & 2013 & $4.0 \mathrm{y}$ & $\begin{array}{l}\text { Awaiting definitive repair at the time of study } \\
\text { censoring }\end{array}$ \\
\hline 13 & D-TGA/VSD/LVOTO & $\mathrm{Y}$ & $\mathrm{Y}$ & & 2015 & $0.8 \mathrm{y}$ & $\begin{array}{l}\text { Awaiting definitive repair at the time of study } \\
\text { censoring }\end{array}$ \\
\hline 14 & D-TGA/VSD/LVOTO & & $\mathrm{Y}$ & & 2015 & $0.5 \mathrm{y}$ & $\begin{array}{l}\text { Awaiting definitive repair at the time of study } \\
\text { censoring }\end{array}$ \\
\hline
\end{tabular}

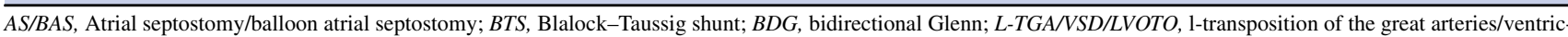
ular septal defect/left ventricular outflow tract obstruction; $D-T G A / V S D / L V O T O$, d-transposition of the great arteries/ventricular septal defect/left ventricular outflow tract.

TABLE E2. Proportion of patients with multiple prerepair procedures by surgical pathway

\begin{tabular}{lccr}
\hline $\begin{array}{c}\text { No. of prerepair } \\
\text { procedures }\end{array}$ & $\begin{array}{c}\text { Fontan, } \\
\mathbf{n}(\%)^{*}\end{array}$ & $\begin{array}{c}\text { Biventricular } \\
\text { repair, n (\%)* }\end{array}$ & Total \\
\hline 0 & $4(14)$ & $23(23)$ & 27 \\
\hline 1 & $6(21)$ & $44(44)$ & 50 \\
\hline 2 & $11(38)$ & $25(25)$ & 36 \\
\hline 3 & $7(24)$ & $6(6)$ & 13 \\
\hline 4 & $1(3)$ & $2(2)$ & 3 \\
Total & 29 & 100 & 129 \\
\hline
\end{tabular}

*Proportion of patients along that surgical pathway. 